\title{
Early history of the stereotactic apparatus in neurosurgery
}

\author{
Maryam Rahman, M.D., Gregory J. A. Murad, M.D., and J Mocco, M.D., M.S. \\ Department of Neurosurgery, University of Florida, Gainesville, Florida
}

\begin{abstract}
Stereotactic neurosurgery has a rich history, beginning with the first stereotactic frame described by Horsley and Clarke in 1908. It is now widely used for delivery of radiation, surgical targeting of electrodes, and resection to treat tumors, epilepsy, vascular malformations, and pain syndromes. These treatments are now available due to the pioneering efforts of neurosurgeons and scientists in the beginning of the 20th century. Their efforts focused on the development of stereotactic instruments for accurate lesion targeting. In this paper, the authors review the history of the stereotactic apparatus in the early 20th century, with a focus on the fascinating people key to its development. (DOI: 10.3171/2009.7.FOCUS09118)
\end{abstract}

\section{KEY WoRdS - stereotactic neurosurgery $\quad$ - stereotactic frame $\quad$ stereotaxy}

$\mathrm{S}$ TEREOTACTIC neurosurgery has a rich history beginning with the first stereotactic frame described by Horsley and Clarke in $1908 .{ }^{17}$ Stereotactic neurosurgery began with intracranial targeting for psychiatric and functional disorders (such as movement disorders). With the discovery of levodopa in 1968 for the treatment of Parkinson disease, the interest in stereotactic surgery plummeted. ${ }^{1}$ However, the advent of CT scanning and other advanced imaging techniques led to the revival of stereotactic neurosurgery with even more applications. It is now widely used for delivery of radiation, surgical targeting of electrodes, and resection to treat tumors, epilepsy, vascular malformations, and pain syndromes. These treatments are now available because of the pioneering efforts of neurosurgeons and scientists in the beginning of the 20th century. Their efforts focused on the development of stereotactic instruments for accurate lesion targeting. We will review the history of the stereotactic apparatus in the early 20th century, with a focus on the fascinating people key to its development.

\section{Stereotaxy}

Interest in the development of stereotactic surgery in humans has been documented in the literature as early as the 19th century. ${ }^{1,10,11,15}$ Around this time the idea that specific parts of the brain had individualized function was beginning to take hold, leading to the study of linking external landmarks of the cranium to cortical topography. The first 3D targeting technique for human neurosurgery was described in a seminal paper published in Brain in 1908 by Victor Horsley (neurophysiologist and neurosurgeon) and Robert Clarke (mathematician) (Fig.
1). ${ }^{11,17}$ Using an apparatus with an electrode guide based on the $3 \mathrm{D}$ cartesian coordinate system, they described lesioning targets in a monkey brain based on skull landmarks. Their apparatus was built from brass and cost $£ 300$ (Fig. 2). ${ }^{36}$ They coined the term "stereotaxis" which is derived from the Greek words stereos meaning "3D" and taxis meaning "orderly arrangement."17,21 Following their initial success, the authors had a disagreement and ceased communication. Some speculate that their separation stemmed from Clarke's jealousy after Horsely was knighted. ${ }^{18}$ Interestingly, upon ceasing their collaboration, some authors have reported that each held on to one half of the stereotactic apparatus, and therefore, neither was unable to use the original device again..$^{11,34}$

Clarke was interested in using the "stereoscopic instrument" in humans and patented the idea in 1914, but he never found a neurosurgeon to help him realize this concept. ${ }^{31,36}$ In 1918, Canadian neuroanatomist Aubrey Mussen collaborated with Horsley and Clarke and subsequently developed a stereotactic apparatus for human use (Fig. 3) ${ }^{32,36}$ During Mussen's first trip to England, he purchased a Horsely-Clarke instrument secondhand for $£ 100 .{ }^{31} \mathrm{He}$ returned to McGill University, experimented with the device, ${ }^{26}$ and developed other instruments with Clarke including a "cyclotome," a probe for making disk-shaped incisions, and a "spherotome" for cutting spherical volumes., ${ }^{9,31}$ Mussen returned to England and commissioned a brass stereotactic apparatus for human use. ${ }^{6}$ However, this device was never used and was found wrapped in newspaper from the 1940s in Mussen's attic. His family donated it to the Montreal Neurological Institute in 1980 after its discovery in his home. ${ }^{30}$

The study of "craniometry" in the early 19th cen- 

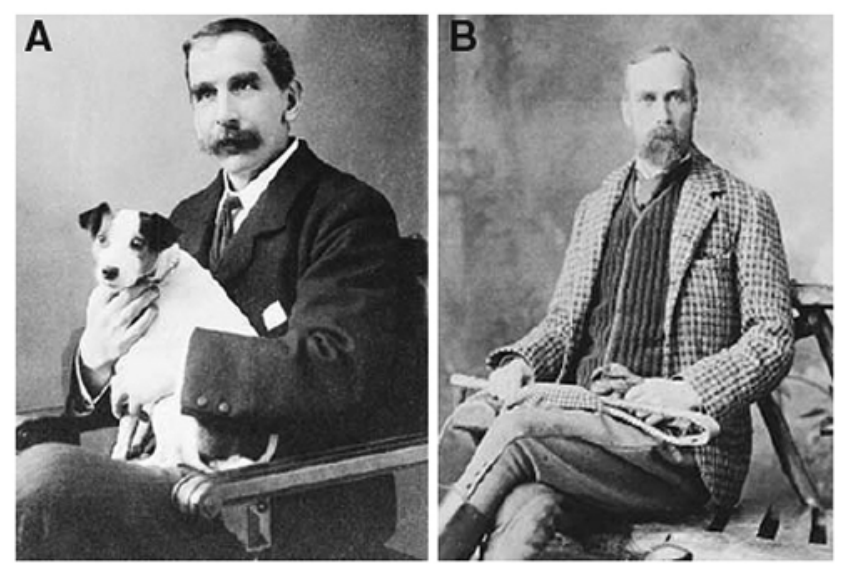

FIG. 1. Photographs of Sir Victor Alexander Haden Horsley (A) and Robert Henry Clarke (B). Reprinted from Pereira EAC et al: Neurosurgery 63:594-607, 2008. Permission granted by Lippincott Williams \& Wilkins.

tury, correlating specific areas of the brain with external skull landmarks, resulted in models such as Wilson's cyrtometer, Kroenlein and Kohler's cephalometers, Broca's craniograph, and Kocher's craniometer (Fig. 4). ${ }^{8,14,19,35}$ All of these devices were built to localize cerebral structures, although they varied in their specific purpose. Kohler's cephalometer was designed to localize the central sulcus, while Kroenlein's device was made to localize the central and sylvian fissures as well as trepanation points for evacuation of hematomas and abscesses. On the other hand, Kocher's craniometer, which was designed after he exchanged ideas with Horsley, consisted of a malleable steel band. This device could be molded to different head shapes and sizes and could localize several structures depending on how it was angled on the head..$^{35}$ Later, in a chapter that Cushing wrote called "Surgery of the Head," Cushing described Kocher's craniometer as one of the four best devices available. ${ }^{35}$ Despite this enthusiasm, these devices were inaccurate because of the variability

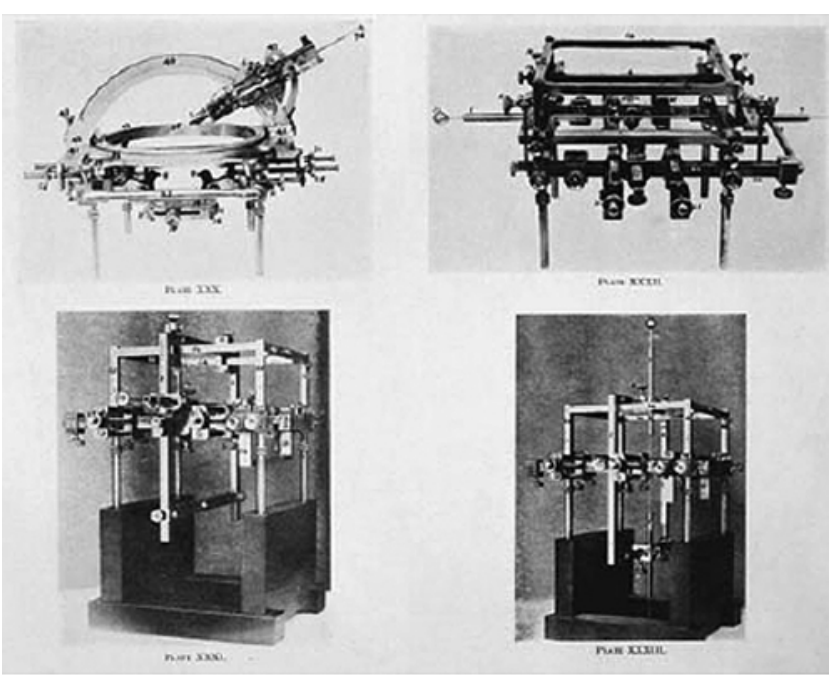

FIG. 2. Photographs of Horsley and Clarke's stereotactic frames. Reprinted from Pereira EAC et al: Neurosurgery 63:594-607, 2008. Permission granted by Lippincott Williams \& Wilkins.

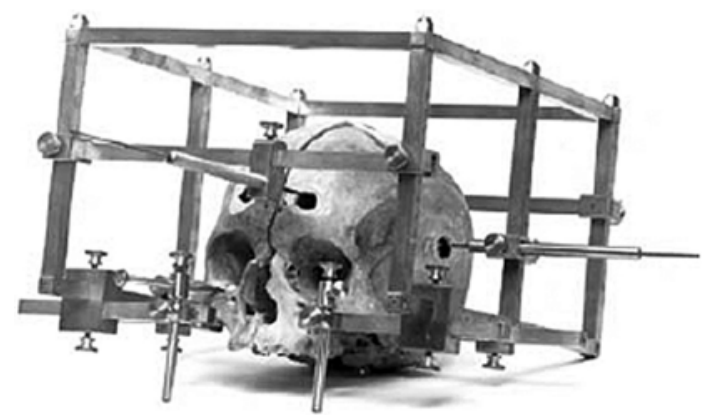

FIG. 3. Photograph of the human stereotactic apparatus developed by Mussen in 1918. Reprinted from Pereira EAC et al: Neurosurgery 63:594-607, 2008. Permission granted by Lippincott Williams \& Wilkins.

of brain structures' correlation with external skull landmarks.

This problem was the research focus of Spiegel et al..$^{37}$ who described stereotaxy in relation to landmarks inside of the skull by using radiographs (the ventricles using pneumoencephalograms and the calcified pineal gland). Their apparatus was similar to the Horsley and Clarke version with an electrode carrier suspended above the head, to be adjusted in all 3 planes independently. They coined to term "stereoencephalotomy" to describe intracranial surgery 3D targeting based on the brain itself. ${ }^{37} \mathrm{In}$ 1936, as Nazi influence was growing, Spiegel left Austria and took a position at Temple Medical School in Philadelphia. He recruited Wycis who worked in Spiegel's lab as a medical student and neurosurgical resident. Interestingly, Wycis funded his way through school by playing semiprofessional baseball and poker. ${ }^{11}$ They described the first use of stereotactic devices in humans with the stereoencephalotome in $1947 .{ }^{37}$ They were amazingly productive and over 20 years published on almost every area of functional neurosurgery. ${ }^{6}$ Their collaboration was very close, and Wycis once described Spiegel as "the only man I know who must have three frontal lobes." 11

Other neurosurgeons were working on similar projects at that time including Jean Talairach in Paris. ${ }^{25,39} \mathrm{Ta}-$ lairach moved to Paris after completing medical school to specialize in psychiatry. He was interested in neuroanatomy, and he found work in the Sainte Anne Hospital, where he would work for almost 70 years until he died in a room that used to be his office ${ }^{38} \mathrm{He}$ participated in World War II, where he earned 3 military medals. Following the war, he was introduced to a neurosurgeon, Marcel David, by 2 famous neurologists, Henri Hacaen and Julian De Ajurriaguera. Given his interest in neuroanatomy, they asked him to design a method to localize deep gray matter structures in the brain. He subsequently switched from psychiatry to neurosurgery, with the specific task of developing a stereotactic frame..$^{25}$ In 1949 he published his initial experiments using a frame based on a rectangular coordinate system that involved grids through which electrodes could be inserted. ${ }^{39}$ The apparatus was designed for targeting the temporal lobes for epilepsy and allowed lateral access. ${ }^{11}$ The grids minimized radiographic image distortion during ventriculograms. To decrease distortion even more, he used the apparatus in a large operating 


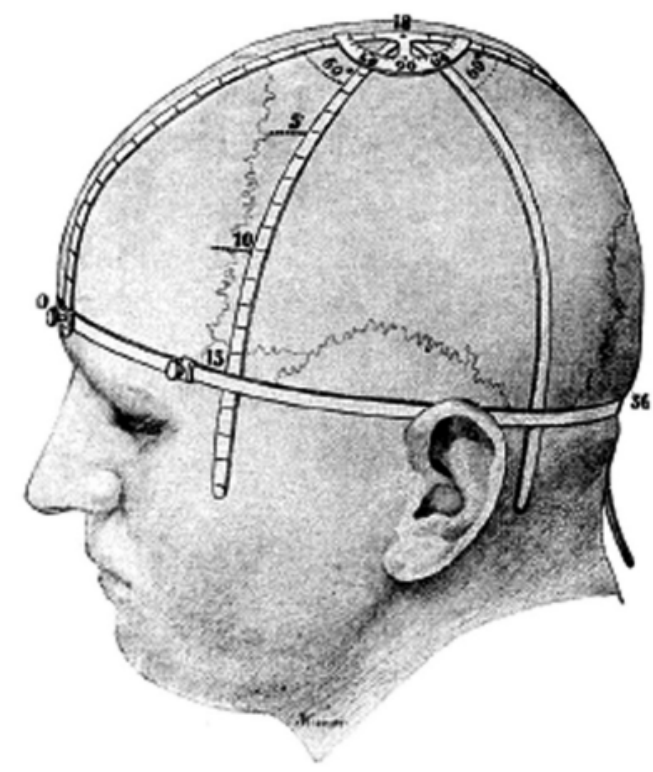

FIG. 4. Drawing of the craniometer developed by Theodore Kocher demonstrating the relationship of the skull sutures to the frame to localize underlying brain structures. Reprinted from Schultke E: Neurosurgery 64:1001-1005, 2009. Permission granted by Lippincott Williams \& Wilkins.

room (called the "chapel") so the x-ray tube was placed up to $5 \mathrm{~m}$ away from the grids. ${ }^{25}$ In 1952 , Talairach proposed the use of the anterior and posterior commissures as reference points for the brain coordinate system. He subsequently used his frame and reference points to map first the gray nuclei and then the entire telencephalon. He continued to work even after his retirement in 1978 until the age of 96 years. ${ }^{25}$

Across the globe, Hirotaro Narabayashi was also developing a frame adapted from the original Horsley and Clarke orthogonal design in Japan. ${ }^{40}$ However, because of Japan's limited exposure to the rest of the world after the war, he was completely unaware of the concurrent work in the US, France, Germany, and Sweden..$^{29}$ In response to Narabayashi's publication "Procain oil blocking of

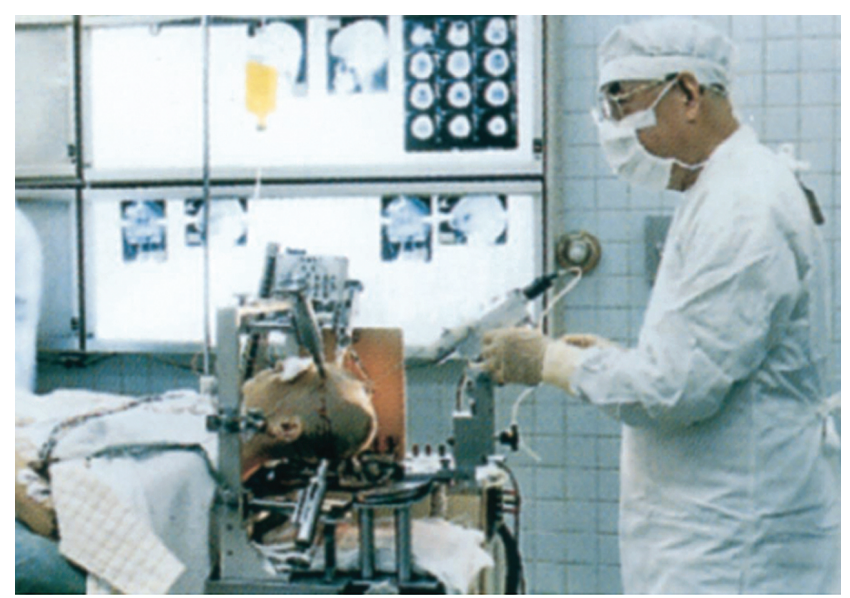

FIG. 5. Photograph of Hirotaro Narabayashi using his stereotactic apparatus. Reprinted from Ohye C et al: Neurosurgery 55:222-227, 2004. Permission granted by Lippincott Williams \& Wilkins.

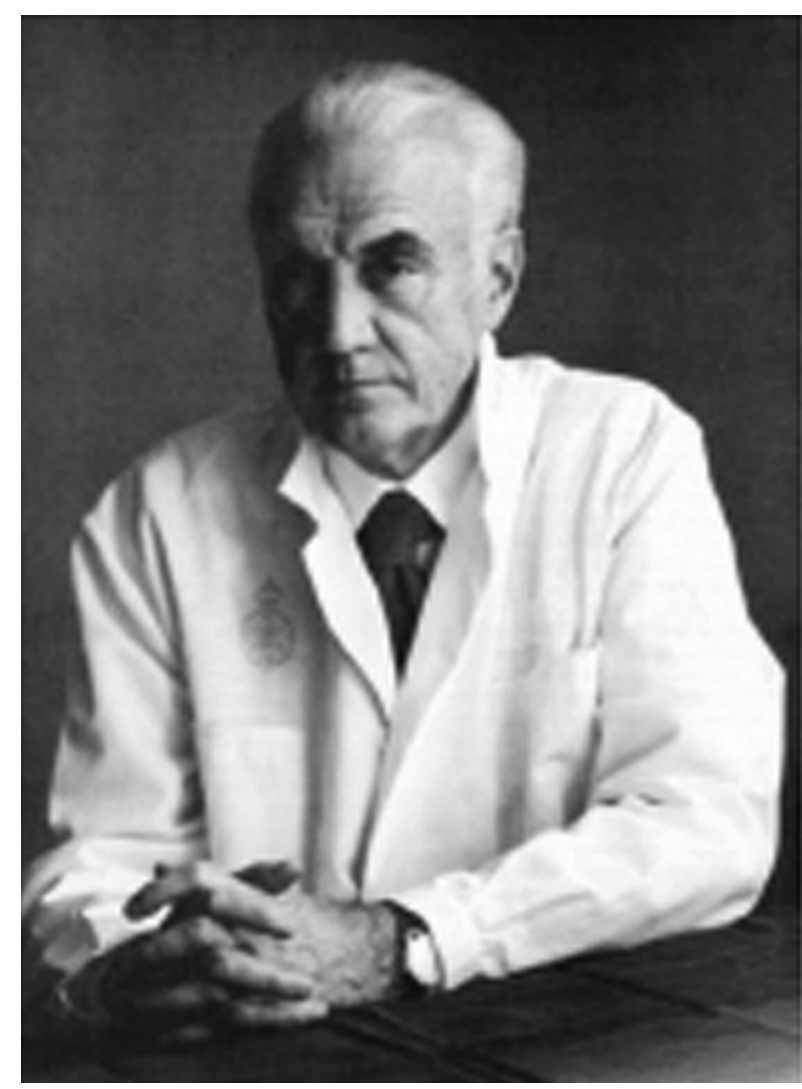

FIG. 6. Photograph of Lars Leksell, who designed an arc-radius stereotactic frame. Reprinted from Hoh DJ et al: Neurosurgery 61:433446, 2007. Permission granted by Lippincott Williams \& Wilkins.

the globus pallidus" in $1956,{ }^{27}$ Spiegel and Wycis wrote, "In this way they try to create the impression that they were the first who performed stereotactic operations on the basal ganglia, not even mentioning with a single word the fact that we have reported such operations repeatedly since 1949." ${ }^{29}$ However, the tension between Narabayashi and Spiegel and Wycis ended when they met at the First International meeting of neurology and neurosurgery in Brussels in 1957. An additional interesting fact is that Narabayashi achieved all of this success at the young age of 35 years. In fact, at the meeting he was asked by one of the meeting participants if he was the son of the famous Dr. Narabayashi. ${ }^{29}$

In the US, Bailey and Stein ${ }^{3}$ exhibited a stereotactic device for intracranial surgery in Atlantic City, New Jersey, in 1951. In the same year, despite isolation similar to Narabayashi, the Germans Riechert and Wolff ${ }^{33}$ described a stereotactic system with a phantom base to indicate the position of the target to verify proper adjustment of the apparatus (Fig. 5). Their system was based on an arc system, like that of Lars Leksell. ${ }^{22}$

Prior to his description of radiosurgery in 1951, Leksell developed a stereotactic frame with skull pin fixation for rigid frame immobilization. ${ }^{23,24}$ Unlike the orthogonal system of Horsley and Clarke, the electrode advanced along a radius of an arc to which the electrode carrier was attached. The position of the arc was adjustable and the electrode pointed to the target, regardless of the angle 
of insertion. ${ }^{11}$ He called this the "arc-radius" and said, "I was born under the sign of the 'archer' and look forward to sharpshoot into the brain." (Fig. 6). ${ }^{21}$ The arc-radius system was subsequently developed into the Todd-Wells stereotactic system (developed by American neurosurgeon Edwin Todd and engineer Trent Wells). The addition of a phantom base to the arc-radius system (similar to Riechert and Wolff's apparatus), led to the Brown-Roberts-Wells frame. ${ }^{5}$

Not all early stereotactic surgical techniques were successful. One such method was the bur hole fixed system. ${ }^{2}$ The instruments were fixed to the skull through a bur hole and allowed electrode movement in the horizontal and vertical planes and depth. This technique was fraught with error since a fraction of a degree in error in the angle at the bur hole site would translate into millimeters of error when the electrode was advanced to its depth. ${ }^{11}$

The art of "sharpshooting into the brain" continued to be advanced through the efforts of multiple neurosurgeons and scientists worldwide including Hecaen et al. ${ }^{16}$ and Guiot et al. ${ }^{13}$ in France, Gillingham ${ }^{12}$ in England, Laitinen and Toivakka ${ }^{20}$ in Finland, Bertrand and Jasper ${ }^{7}$ in Canada, Velasco Suarez and Escobedo ${ }^{41}$ in Mexico, Obrador $^{28}$ in Spain, and Bechtereva et al. ${ }^{4}$ in Russia, among others. ${ }^{11}$ The leaders in the field of stereotaxy created the International Society for Research in Stereoencephalotomy during an international symposium in Philadelphia in 1961. As the word "stereotaxic" was replaced with the word "stereotactic" (ending in the Latin word for "to touch"), this society changed its name to the World Society for Stereotactic and Functional Neurosurgery. ${ }^{11}$

Stereotactic neurosurgery continued to evolve in the 1970s and 1980s with the advent of CT scanning and MR imaging. Using traditional reference points such as anterior and posterior commissures as well as skull landmarks, precise imaging has precluded the use of a stereotactic frame. Frameless stereotaxy is becoming an increasingly common tool for neurosurgeons. Stereotactic neurosurgery now covers much more than functional neurosurgery and lays claim to multiple, sophisticated stereotactic frames, apparatuses, and frameless localization techniques. The utility of these instruments would not exist without the vision and dedication of our early pioneers.

\section{Conclusions}

Stereotactic neurosurgery began with the development of an orthogonal frame for animal use by Horsley and Clarke and has become an active field of research and treatment for human pathology. Advances in stereotaxy have allowed for targeting of intra- and extracranial lesions that were untreatable in the past. The early neurosurgeons and scientists of stereotaxy have laid the groundwork for future innovation. Due to their efforts, stereotactic neurosurgery is now an independent and growing field of study.

\section{Disclaimer}

The authors report no conflict of interest concerning the mate- rials or methods used in this study or the findings specified in this paper.

\section{References}

1. al-Rodhan NR, Kelly PJ: Pioneers of stereotactic neurosurgery. Stereotact Funct Neurosurg 58:60-66, 1992

2. Austin G, Lee A: A plastic ball and socket type of stereotaxic detector. J Neurosurg 15:264-268, 1958

3. Bailey P, Stein SN: A stereotaxic apparatus for use on the human brain. Atlantic City, NJ: AMA Scientific Exhibit, 1951

4. Bechtereva NP, Bondartchuk AN, Smirnov VM, Meliutcheva LA, Shandurina AN: Method of electrostimulation of the deep brain structures in treatment of some chronic diseases. Confin Neurol 37:136-140, 1975

5. Benedict SH, Bova FJ, Clark B, Goetsch SJ, Hinson WH, Leavitt DD, et al: Anniversary paper: the role of medical physicists in developing stereotactic radiosurgery. Med Phys 35:4262-4277, 2008

6. Bertrand G: Stereotactic surgery at McGill: the early years. Neurosurgery 54:1244-1252, 2004

7. Bertrand G, Jasper H: Microelectrode recording of unit activity in the human thalamus. Confin Neurol 26:205-208, 1965

8. Broca P: [Memoir on the craniograph and some of its applications.] Mémoires de la Société d'Anthropologie de Paris, $1863(\mathrm{Fr})$

9. Clarke RH: Investigation of the Central Nervous System. Part I: Methods and Instruments. Baltimore: Johns Hopkins Press, 1920

10. Dittmar C: Ueber die Lage des soggenannten Gefaesszentrums in der Medulla oblongata. Ber saechs Ges Wiss, Leipzig (Math phys) 25:449-469, 1873

11. Gildenberg P: The history of stereotactic neurosurgery. Neurosurg Clin N Am 1:765-780, 1990

12. Gillingham FJ: Small localised surgical lesions of the internal capsule in the treatment of the dyskinesias. Confin Neurol 22:385-392, 1962

13. Guiot G, Hardy J, Albe-Fessard D: Délimitation précise des structures sous-corticales et identification des noyaux thalamiques chez l'homme par l'électrophysiologie stéréotaxique. Neurochirurgie 5:1-18, 1962

14. Hare A: Lectures on cranial surgery. The Lancet, 1888

15. Hassler R, Riechert T: [A case of bilateral fornicotomy in socalled temporal epilepsy.] Acta Neurochir (Wien) 5:330340, 1957 (Ger)

16. Hecaen H, Talairach J, David M, Dell, MB: Coagulations limitées du thalamus dans les algies du syndrome thalamique. Rev Neurol 81:917-931, 1949

17. Horsley V, Clarke RH: The structure and functions of the cerebellum examined by a new method. Brain 31:45-124, 1908

18. Kelly PJ: Comments on "Stereotactic neurosurgery in the United Kingdom: the hundred years from Horsley to Hariz." Neurosurgery 63:607, 2008

19. Kohler: Deutsche Med Wochenschrift 48, 1889, in Kocher T: [Commotio cerebri, intracranial pressure and surgical intervention in diseases of the brain.] Vienna: Alfred Hölder Verlag, p 423, 1901 (Ger)

20. Laitinen L, Toivakka E: Locating brain tumours through depth EEG probes. Confin Neurol 34:101-105, 1972

21. Lee NIS, Schiff PB, Sisti MB, Germano IM: Historical perspective and basic principles of radiation physics and biology, in Germano IM (ed): LINAC and Gamma Knife Radiosurgery. Rolling Meadows, IL: The American Association of Neurological Surgeons, 1999, pp 3-10

22. Leksell L: A stereotaxic apparatus for intracerebral surgery. Acta Chir Scand 99:229-233, 1949

23. Leksell L: The stereotaxic method and radiosurgery of the brain. Acta Chir Scand 102:316-319, 1951

24. Leksell L: Stereotaxic radiosurgery in trigeminal neuralgia. Acta Chir Scand 137:311-314, 1971 
25. Mazoyer B: In memoriam: Jean Talairach (1911-2007): a life in stereotaxy. Hum Brain Mapp 29:250-252, 2008

26. Mussen AT: Notes on the movements of the tongue from stimulation of the twelfth nucleus, root and nerve. Brain 32:206, 1909

27. Narabayashi H, Okuma T, Shikiba S: Procaine oil blocking of the globus pallidus. AMA Arch Neurol Psychiatry 75:3648, 1956

28. Obrador S: A simplified neurosurgical technique for approaching and damaging the region of the globus pallidus in Parkinson's disease. J Neurol Neurosurg Psychiatry 20:47-49, 1957

29. Ohye C, Fodstad H: Forty years with Professor Narabayashi. Neurosurgery 55:222-227, 2004

30. Olivier A, Bertrand G, Picard C: Discovery of the first human stereotactic instrument. Appl Neurophysiol 46:84-91, 1983

31. Pereira EA, Green AL, Nandi D, Aziz TZ: Stereotactic neurosurgery in the United Kingdom: the hundred years from Horsley to Hariz. Neurosurgery 63:594-597, 2008

32. Picard C, Olivier A, Bertrand G: The first human stereotaxic apparatus. The contribution of Aubrey Mussen to the field of stereotaxis. J Neurosurg 59:673-676, 1983

33. Riechert T, Wolff M: [Development and clinical aspect of methodical brain surgery.] Med Klin 46:609-611, 1951 (Ger)

34. Schaltenbrand G: Personal observations on the development of stereotaxy. Confin Neurol 37:410-416, 1975
35. Schultke E: Theodor Kocher's craniometer. Neurosurgery 64: 1001-1005, 2009

36. Schurr PH, Merrington WR: The Horsley-Clarke stereotaxic apparatus. Br J Surg 65:33-36, 1978

37. Spiegel EA, Wycis HT, Marks M, Lee AJ: Stereotaxic apparatus for operations on the human brain. Science 106:349-350, 1947

38. Talairach J: Souvenirs des études stéréotaxiques du cerveau humain. Une vie, une équipe, une méthodologie. L'Ecole de Sainte-Anne. Montrouge: John Libbey Eurotext, 2007, p 131

39. Talairach J, Hecaen H, David M, Mounier M: Recherches sur la coagulation thérapeutique des structures sous-corticales chez l'homme. Rev Neurol 81:4-24, 1949

40. Uchimura Y, Narabayashi H: [Stereoencephalotomy.] Psychiat Neurol Jpn 52:265-270, 1951 (Jpn)

41. Velasco Suarez MM, Escobedo FR: Stereotaxic intracerebral instillation of dopa. Confin Neurol 32:149-157, 1970

Manuscript submitted May 15, 2009.

Accepted July 8, 2009.

Address correspondence to: Maryam Rahman, M.D., Department of Neurosurgery, University of Florida, Box 100265, Gainesville, Florida 32610-0265. email: maryam.rahman@ neurosurgery.ufl.edu. 